\title{
Low-temperature oxidative asphaltenes liquefaction for petrochemicals: fact or fiction?
}

\author{
Natalia Montoya Sánchez ${ }^{1} \cdot$ Arno de Klerk ${ }^{1}$
}

Received: 1 June 2015/ Accepted: 27 January 2016/Published online: 12 February 2016

(C) The Author(s) 2016. This article is published with open access at Springerlink.com

\begin{abstract}
Asphaltene is the heavy and heteroatom-rich fraction of petroleum that is rejected during a solvent deasphalting process. In patent literature there are claims that state that this material can be converted into an aromatic petrochemical feedstock by oxidative liquefaction at low temperature. To evaluate the validity of these claims, asphaltenes from an industrial solvent deasphalting process were oxidized with dry and water-saturated air at temperatures in the range $45-100{ }^{\circ} \mathrm{C}$. Infrared spectroscopy of the oxidized product confirmed that oxygen was incorporated as $\mathrm{C}=\mathrm{O}$ and $\mathrm{C}-\mathrm{O}$. Under all experimental conditions studied little oxidative degradation was observed that would lead to the production of a petrochemical feedstock. Nevertheless, some observations of scientific value were made about the low-temperature conversion of asphaltenes. During autoxidation with dry air, the $n$-pentane-insoluble fraction increased. On the contrary, when oxidation was conducted with water-saturated air, the formation of additional $n$-pentane-insoluble material was suppressed. Mild heating of asphaltenes under nitrogen atmosphere also caused the $n$-pentane-insoluble content to increase. Spectroscopic evidence showed that esters are formed during oxidation at $\sim 100{ }^{\circ} \mathrm{C}$. The temperature dependence of this reaction was explained and a possible reaction pathway for cycloalkane to ester conversion was presented. Ester selectivity was determined by the competition between hydrogen abstraction and $\beta$-scission of the alkoxy radical.
\end{abstract}

Natalia Montoya Sánchez

nmontoya@ualberta.ca

1 Department of Chemical and Materials Engineering, University of Alberta, Edmonton, AB T6G 2V4, Canada
Keywords Asphaltenes autoxidation - Wet oxidation . Heating of asphaltenes

\section{Introduction}

Asphaltenes are a solubility class. Industrially it is produced as the rejection product from a solvent deasphalting process to produce deasphalted oil, which is the upgraded product. The asphaltenes fraction contains the heaviest and most polar compounds in crude oil, as well as a significant fraction of heteroatoms and metals. Compared to bitumen, asphaltenes are more aromatic in nature, and have an even lower H:C ratio (1.1 approximately) [1]. Even though, asphaltenes are considered the least favorable fraction for upgrading, they have the potential to be converted to higher value liquid products, including petrochemicals. Industrially, there are pathways for doing so, but more efficient alternative conversion chemistries are required to make it economically attractive.

Traditionally the conversion of asphaltenes to petrochemical products is not considered. There are limited markets for asphalt and heavy oil. Upgrading to lighter oil by standard refining technologies, such as delayed coking, can achieve liquid yields of the order of 40-50\% [14]. In heavy oils that contain a significant fraction of asphaltenes, rejecting most or all of the asphaltenes as waste material could be an expensive strategy. For example, in Canadian oilsand-derived bitumen the asphaltenes fraction represents more than $10 \mathrm{wt} \%$ of the total bitumen [5], often close to $15 \mathrm{wt} \%$.

According to the patent literature, low-temperature oxidation of asphaltenes might be an alternative strategy to add value to this material [6, 17]. Lighter oil-soluble oxygenates, or water-soluble oxygenates, which would be 
rich in phenolic compounds when derived from asphaltenes oxidation, could have value as petrochemical feedstocks. To produce petrochemicals, further separation would be required, but such separation technology is known from the recovery of phenolic compounds from coal liquids and ammoniacal water [7].

The patent literature $[6,17]$ claims that contacting asphaltenes with an oxygen-containing gas, e.g., air, at temperatures below $100{ }^{\circ} \mathrm{C}$ produces liquid products. It was reported that the liquid yield of pentane extractable materials increased after oxidation, with liquid yields of the order of $15 \mathrm{wt} \%$ being achieved [17]. Particularly, it has been pointed out that oxidation at temperatures close to $50{ }^{\circ} \mathrm{C}$ produced liquid products suitable to be used as drying oils and refinery feedstocks for production of organic chemicals $[6,17]$. In addition, it has been suggested that air saturated with water vapor is a significantly better oxidizing agent able to increase the liquid yield [17]. The oxidation can be performed using a force draft oven or a packed-bed reactor. Under these premises, it seems that low-temperature oxidation of asphaltenes might be possible and that at least part of the asphaltenes can be transformed from a low-value solid to a higher value petrochemical feedstock, before the asphaltenes is further upgraded using conventional technologies.

Unfortunately the literature also contains reports that state that oxidation, even at temperatures as low as $60^{\circ} \mathrm{C}$ and oxidation times as long as $229 \mathrm{~h}$ at $130{ }^{\circ} \mathrm{C}$, leads to substantial hardening with little lighter liquid products being produced $[2,8,11,18]$. These studies all dealt with heavy oils, rather than just the asphaltenes fraction. Yet, it cast doubt on the validity of the claims in the patent literature. The purpose of this concise experimental study was exploring and validating the possibility of using lowtemperature oxidative asphaltenes liquefaction as upgrading strategy. The conversion strategies outlined in the patent literature were repeated and the usefulness of this strategy for petrochemical production from asphaltenes was evaluated.

\section{Experimental section}

\section{Materials}

The asphaltenes were obtained from an industrial $\mathrm{C}_{5}$ solvent deasphalting process at the Long Lake Upgrader in Alberta, Canada and were supplied by Nexen Energy ULC. Selected properties of these asphaltenes are provided in Table 1. $n$-Pentane (98 wt\%) was used as solvent and it was purchased from Sigma-Aldrich. High-purity nitrogen (99.998\%) and extra-dry air were obtained from Praxair. All chemicals were used without further purification.
Distilled water was prepared using a Millipore water purification system.

It should be noted that the industrial nature of the raw material has some implications for its properties, particularly on the asphaltene content. Traditionally, in solvent deasphalting processes the feed and the solvent are mixed together, in ratios varying from 3:1 up to 10:1 [10], leading to the precipitation and separation of the asphaltene fraction. Neither the solvent to feed ratio, nor the settling time allowed for phase separation is near that of the laboratory precipitation procedure. Although, the efficiency of deasphalting in such cases may differ, it has been reported to being up to $80 \%$ efficient compared to rigorous laboratory precipitation [10]. As a consequence, the material present in the separated asphaltene fraction is not only asphaltenes. In fact, the term asphaltenes being a solubility class has a relative meaning and it should not be taken on an absolute basis, as one can do with a compound class. The industrially obtained raw material has an actual asphaltene content of $\sim 70 \mathrm{wt} \%$. This content was measured according to standard laboratory techniques in which the solvent to feed ratio (40:1) exceeds by far the industrial conditions. Details are provided in the analysis section.

\section{Procedure}

Oxidation of asphaltenes was performed based on the reaction conditions and the experimental setup reported in the patent literature [17]. Two types of experiments were carried out, so that dry air and moist air were used as the oxidizing agents.

The equipment employed for the first part of the study, namely oxidation of asphaltenes using dry air, consisted of a Yamato DP43 oven, which was connected to a dry air supply line. The air flow was controlled by a glass Supelco rotameter and adjusted to $250 \mathrm{~mL} / \mathrm{min}$. The oven temperature was monitored with a thermometer. For each oxidation experiment, three samples of asphaltenes weighing approximately $1.2 \mathrm{~g}$ were used. The samples were placed inside the oven after it reached a constant temperature, and they were heated during $16 \mathrm{~h}$. Experiments were performed at four different temperatures: $45,56,86$, and $100{ }^{\circ} \mathrm{C}$. The products were weighted and analyzed. Blank experiments using an inert nitrogen atmosphere were also carried out.

The apparatus used for the second type of experiments performed in this study, namely oxidation of asphaltenes using moist air, consisted of a stainless steel column of $2.56 \mathrm{~cm}$ (1 inch) internal diameter, and $25.66 \mathrm{~cm}$ length (10 inches), which was connected to a moist air line supply. The moist air was fed from the bottom to the top of the column and it was produced by bubbling air through water in a $250-\mathrm{mL}$ Erlenmeyer flask. In addition, the air flow was regulated with a glass Supelco rotameter and it was 
Table 1 Properties of asphaltenes from industrial $\mathrm{C}_{5}$ solvent deasphalting process

\begin{tabular}{lc}
\hline Property & $\begin{array}{c}\text { Industrially obtained } \\
\text { asphaltenes }\end{array}$ \\
\hline Asphaltene content $(\mathrm{wt} \%)^{\mathrm{a}}$ & $66.9 \pm 0.6$ \\
Density $(\mathrm{kg} / \mathrm{L})^{\mathrm{b}}$ & $1.1 \pm 0.1$ \\
${ }^{1} \mathrm{H}$ NMR aliphatic:aromatic ratio & $7.2 \pm 0.2$ \\
Elemental Composition (wt\%) & \\
$\mathrm{H}$ & $8.1 \pm 0.1$ \\
$\mathrm{C}$ & $82.1 \pm 0.1$ \\
$\mathrm{~N}$ & $1.2 \pm 0.0$ \\
$\mathrm{O}$ & $0.9 \pm 0.3$ \\
$\mathrm{~S}$ & $7.8 \pm 0.1$ \\
\hline
\end{tabular}

a Asphaltenes precipitated with $n$-pentane

b Density by liquid displacement

adjusted to a flow rate of 3 standard cubic feet per hour per $100 \mathrm{~g}$ of asphaltenes. A Lindberg Blue $\mathrm{M}$ tube furnace, coupled with a Thermo Fisher temperature controller was used as heating mantle.

For each oxidation experiment, the column was packed as a fixed-bed reactor. Thus, layers of glass beads, of approximately $5 \mathrm{~cm}$ ( 2 in) length, were symmetrically placed at the top and bottom of the column. Round pieces of a fine stainless steel mesh were situated at the ends of these glass beads. A bed of asphaltenes of about $15 \mathrm{~cm}(6$ in) was situated in the middle of the column. The packed column was heated up to the reaction temperature. A typical heat-up time was $8 \mathrm{~min}$. Oxidation reactions were conducted at 52 and $100{ }^{\circ} \mathrm{C}$, for $2 \mathrm{~h}$. Additional experiments at $52{ }^{\circ} \mathrm{C}$ for different reaction times $(2,4$ and $8 \mathrm{~h})$ were also performed. Note that some experiments used dry air for comparison purposes. Products were collected for further analysis.

\section{Analysis}

The following analyses were performed to characterize the reaction products:

(a) The asphaltenes content of the products was determined by precipitation with $n$-pentane. The procedure is as follows: $1 \mathrm{~g}$ of sample was weighted and mixed with $40 \mathrm{~mL}$ of $n$-pentane in a $250-\mathrm{mL}$ flask. Then, the mixture was continuously stirred with a magnetic bar, at room temperature for $1 \mathrm{~h}$. After that the mixture was left without stirring for a period of $24 \mathrm{~h}$. The mixture was filtered with a $0.22 \mu \mathrm{m}$ Millipore nitrocellulose membrane filter under vacuum conditions and it was rinsed with fresh $n$-pentane until the eluent became colorless. The filter with the precipitated asphaltenes was transferred to an aluminum cup and was left in a fume hood for $48 \mathrm{~h}$ to ensure complete evaporation of the solvent. Finally, the dried asphaltenes were weighed and the asphaltenes content was calculated.

It is worth mentioning that the method used in the present study to determine the asphaltenes content of the samples does not allow for differentiating between asphaltenes and coke. Nonetheless, it is very unlikely that a significant amount of coke would have been produced at the reaction conditions, i.e., low temperature and atmospheric pressure. Thermal conversion of asphaltenes resulting in the formation of coke has been reported for reaction under more severe conditions. For instance, Cold lake-derived asphaltenes has been reported to form coke by conversion at $400{ }^{\circ} \mathrm{C}$ [24]. In addition, it has been stated that the presence of heptane-soluble material inhibits formation of coke by asphaltenes. As described in the materials section, although the raw material or industrial asphaltenes used in this study are mostly asphaltenes, it contains about $\sim 30 \mathrm{wt} \%$ of other components (maltenes) from oil.

(b) Infrared spectroscopy was used to provide information about the chemical changes in the asphaltenes related to the oxidation reactions. An ABB MB3000 Fourier Transform infrared spectrometer with Horizon MB FTIR software was used to collect the infrared spectra. The spectrometer was equipped with a Pike MIRacle Reflection attenuated total reflectance (ATR) diamond crystal plate. The infrared analysis was performed at a resolution of $4 \mathrm{~cm}^{-1}$ and an average of 120 scans over the spectral region of $4000-600 \mathrm{~cm}^{-1}$. To perform comparisons at specific wave numbers, all spectra were scaled based on the symmetric deformation mode of the methyl $\left(-\mathrm{CH}_{3}\right)$ groups at $\sim 1375 \mathrm{~cm}^{-1}$. The underlying assumption was that oxidation of methyl groups is more difficult and under the mild oxidation conditions investigated, little oxidation of methyl groups was anticipated. This is based on the two orders of magnitude lower oxidation rate of methyl groups compared to secondary aliphatic carbons [12].

(c) The micro carbon residue (MCR) of the products was calculated from thermogravimetric analysis. A Mettler Toledo TGA/DSC1 with LF furnace, sample robot and, MX5 internal microbalance was used. The resolution of the balance was $0.1 / 1 \mu \mathrm{g}$. Analyses were carried out under nitrogen atmosphere. All micro carbon residue measurements were determined in accordance with the standard test method ASTM D4530. 


\section{Results}

\section{Low-temperature dry autoxidation of asphaltenes}

The first part of the work dealt with the autoxidation (oxidation with air) of asphaltenes in the absence of added water. In this case, oxygen from dry air was responsible for producing the oxidized products. Reactions were carried out for $16 \mathrm{~h}$ at $45,56,86$, and $100{ }^{\circ} \mathrm{C}$. In addition, blank experiments using an inert atmosphere (air substituted with $\mathrm{N}_{2}$ ) were performed to determine whether heating during product workup has an effect on its own.

After reaction, the asphaltenes content of the products was measured, and then compared with the asphaltenes content of the raw material (Fig. 1). There was little difference between the asphaltenes content of the asphaltenes feed and that of the samples that were oxidized at 45, 56 and $86^{\circ} \mathrm{C}$, respectively. In this temperature range, the difference in the asphaltene content between the samples that were oxidized and the ones that were just heated under nitrogen atmosphere was also too small to be statically meaningful. It should further be noted that the increase in mass due to oxygen incorporation and the decrease in mass due to production of volatile oxidation products were minor; in fact, the mass of the oxidized products decreased in approximately $0.01-0.03 \mathrm{wt} \%$ compared to the mass of the initial asphaltenes feed.

The impact of oxidation on the product properties was more apparent when the reaction temperature was increased to $100{ }^{\circ} \mathrm{C}$. In this case both autoxidation and heating under inert atmosphere affected the asphaltenes content of the products. For the oxidized sample an increase in the asphaltenes content from $66.9 \pm 0.6$ to $76.3 \pm 1.9$ wt $\%$ was observed. On heating, the asphaltenes content of the product increased to $71.3 \pm 1.2 \mathrm{wt} \%$. It is

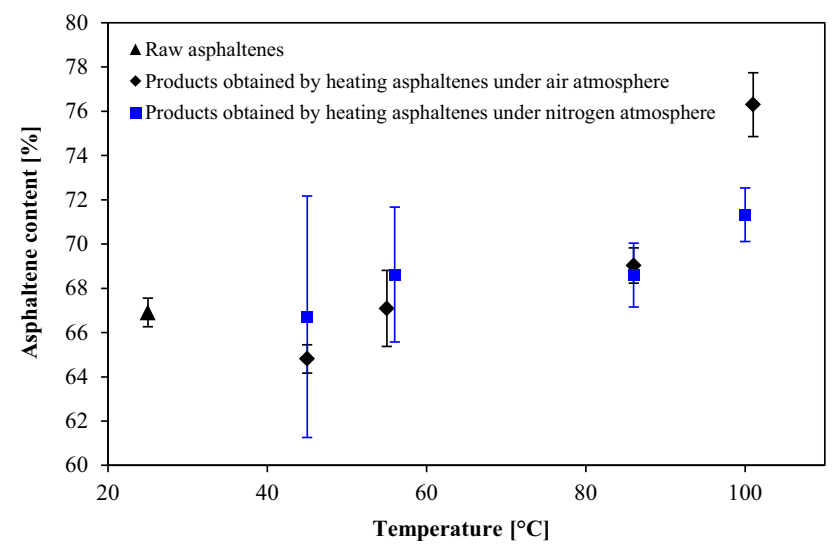

Fig. 1 Asphaltenes content of the products obtained by heating asphaltenes feed in air and nitrogen atmospheres for $16 \mathrm{~h}$ at 45,55 , 86 , and $100{ }^{\circ} \mathrm{C}$ evident that the increase in the asphaltenes content of the oxidized product is not only a consequence of the chemistry of autoxidation, but there is also a contribution because of thermal effect. Directionally the effect of oxidation was the opposite of what was claimed in the patent literature [6, 17].

A comparison of the infrared spectra of the raw asphaltenes feed and the total oxidized products from oxidation at different conditions are presented (Fig. 2). The presence of $\mathrm{C}=\mathrm{O}$ and $\mathrm{C}-\mathrm{O}$ stretching vibrations in the oxidized products confirmed the incorporation of oxygen in the asphaltenes structure due to autoxidation. Infrared spectroscopy is particularly sensitive for detecting carbonoxygen vibrations, which have high absorptivity in the infrared spectrum.

The spectra showed some diversity in the chemical environment of the carbonyl groups and the $\mathrm{C}-\mathrm{O}$ functionality [20]. Prominent absorption bands in the $1713-1742 \mathrm{~cm}^{-1}$ region as well as in the $1202-1234 \mathrm{~cm}^{-1}$ region were found. A considerable increase of the $\mathrm{C}=\mathrm{O}$ and $\mathrm{C}-\mathrm{O}$ stretching vibrations was observed in the samples that reacted at 86 and $101{ }^{\circ} \mathrm{C}$, whereas, less intense absorption bands were noted in the sample oxidized at $55^{\circ} \mathrm{C}$. These interactions were not observed in the products obtained at $45{ }^{\circ} \mathrm{C}$. Absorption bands indicating the presence of other oxygen-containing functional groups, such as sulfoxides, were minor. Even though no quantification was made, a relative comparison is possible. The infrared analysis suggested a higher extent of oxidation when increasing the temperature.

Some semi-quantitative information was extracted from the IR analyses (Table 2). The relative peak intensity of the $\mathrm{C}=\mathrm{O}$ and $\mathrm{C}-\mathrm{O}$ vibrations in each sample is an indication of the relative increase or decrease for each group. The absorptivities for the different vibration bands are different and observed changes should not be over-interpreted.

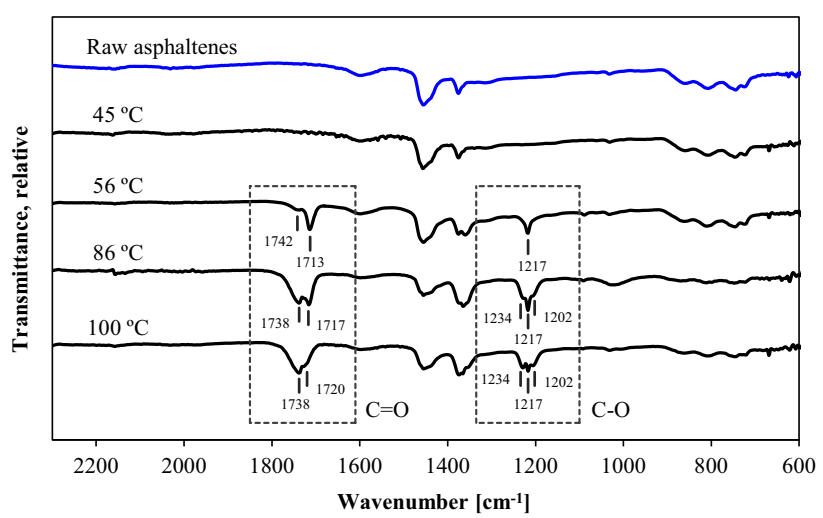

Fig. 2 Infrared spectra of the raw asphaltenes and the total oxidized product after $16 \mathrm{~h}$ oxidation at $45,56,86$, and $100^{\circ} \mathrm{C}$ 
Table 2 Relative peak intensities of absorptions at different regions of the IR spectra for oxidized asphaltenes

\begin{tabular}{|c|c|c|c|c|c|c|c|c|}
\hline \multirow[t]{2}{*}{ Stretching vibrations $\left[\mathrm{cm}^{-1}\right]$} & \multirow[t]{2}{*}{ Functional group } & \multicolumn{3}{|c|}{ Total oxidized product } & \multicolumn{4}{|c|}{ Oxidized maltenes fraction } \\
\hline & & $56^{\circ} \mathrm{C}$ & $86^{\circ} \mathrm{C}$ & $100{ }^{\circ} \mathrm{C}$ & $45^{\circ} \mathrm{C}$ & $56^{\circ} \mathrm{C}$ & $86^{\circ} \mathrm{C}$ & $100^{\circ} \mathrm{C}$ \\
\hline $1734-1442$ & $\mathrm{C}=\mathrm{O}$ & 0.2 & 1.1 & 1.0 & - & 0.6 & 0.2 & 1.0 \\
\hline $1713-1722$ & $\mathrm{C}=\mathrm{O}$ & 1.4 & 1.7 & 1.0 & 0.8 & 1.0 & 0.2 & 1.0 \\
\hline 1454 & $\mathrm{C}-\mathrm{H}$ & 1.6 & 0.9 & 1.0 & 2.6 & 1.8 & 2.3 & 1.0 \\
\hline $1230-1259$ & $\mathrm{C}-\mathrm{O}$ & - & 1.0 & 1.0 & 0.7 & 0.8 & 0.5 & 1.0 \\
\hline $1217-1219$ & $\mathrm{C}-\mathrm{O}$ & 1.1 & 1.4 & 1.0 & 1.4 & 1.8 & - & 1.0 \\
\hline $1200-1203$ & $\mathrm{C}-\mathrm{O}$ & - & 1.1 & 1.0 & - & 0.8 & 0.5 & 1.0 \\
\hline
\end{tabular}

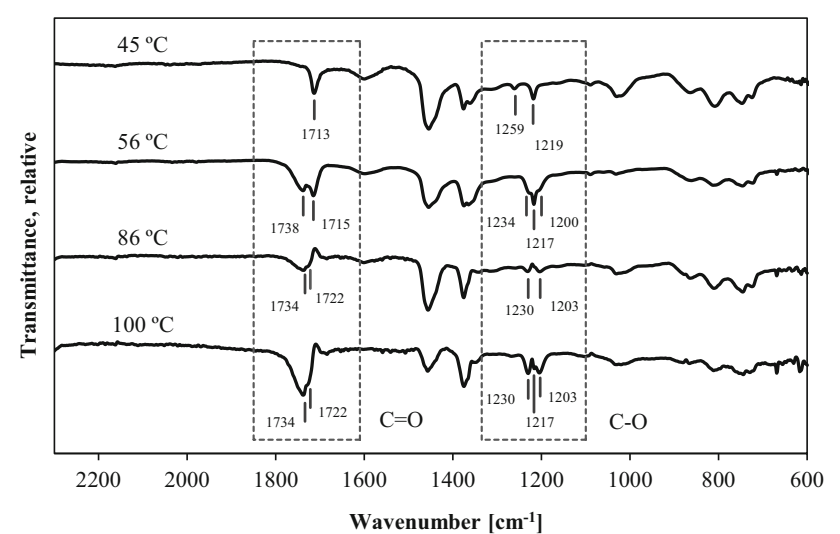

Fig. 3 Infrared spectra of the maltenes fraction separated from the oxidized products obtained after $16 \mathrm{~h}$ oxidation at $45,56,86$, and $100{ }^{\circ} \mathrm{C}$

After reaction, the asphaltenes fraction of the oxidized samples was precipitated using $n$-pentane (using the same procedure to measure asphaltenes content and separate maltenes). The products soluble in the pentane were recovered, and a brown, oily extract was obtained. The infrared spectra of the different extracted liquid products were compared (Fig. 3). In all the samples both $\mathrm{C}=\mathrm{O}$ and $\mathrm{C}-\mathrm{O}$ absorption bands were observed indicating the presence of oxygenated compounds. The intensity of these absorption bands changed with the change in temperature, which is indicative of changes in the oxidation selectivity.

The infrared spectra of the products obtained in the blank experiments were also compared. Neither the products obtained after heating nor the ones extracted with $n$ pentane showed any signs of change in their infrared spectra. This is not surprising because infrared analysis is not a sensitive technique to detect small changes in hydrocarbon composition.

The micro carbon residue of the raw asphaltenes, the oxidized asphaltenes and the ones that were heated under inert atmosphere was measured and compared (Table 3). There was little difference between the MCR value of the feed asphaltenes and that of the reaction products. Only a minor increase in MCR value of the oxidized products obtained at 86 and $100{ }^{\circ} \mathrm{C}$ was observed. At these temperatures, autoxidation might have affected the asphaltenes structure in such a way that products are slightly more prone to form coke.

The kinetics of the reactions taking place during the autoxidation and blank experiments might be slow and most likely not favored by low temperature. As a result, for the selected reaction conditions no significant changes were initially observed. Probably, when experiments were performed at $100{ }^{\circ} \mathrm{C}$, the temperature was high enough to accelerate the reaction process. After reaction at $100{ }^{\circ} \mathrm{C}$ small changes in the product properties were found, notably, higher asphaltenes content.

\section{Low-temperature water-assisted oxidation of asphaltenes}

Literature indicates that the presence of water has a positive effect in the low-temperature oxidation of heavy oil and asphaltenes $[13,17]$. The second part of the work was, therefore, focused on the oxidation of asphaltenes using air saturated with water vapor, or moist air. Some control experiments were also performed in which dry air was used at the same conditions.

As before, the asphaltenes content of the oxidized products was measured after oxidation and compared with the raw material (Table 4). The asphaltene content of the products increased from $66.9 \pm 0.6 \mathrm{wt} \%$ to a maximum of $70.5 \pm 1.1 \mathrm{wt} \%$ after $8 \mathrm{~h}$ of reaction at $52{ }^{\circ} \mathrm{C}$. Although reactions at $52{ }^{\circ} \mathrm{C}$ were conducted at different reaction times, the differences in the asphaltenes contents and MCR values of the respective oxidized products were too small to be statistically meaningful. No trend for changes in the asphaltenes content with oxidation time was observed for oxidation at $52{ }^{\circ} \mathrm{C}$.

The formation of $\mathrm{C}=\mathrm{O}$ and $\mathrm{C}-\mathrm{O}$ functional groups were nevertheless confirmed by infrared spectroscopy (Fig. 4). 
Table 3 Micro carbon residue data for raw asphaltenes, oxidized asphaltenes, and asphaltenes heated in nitrogen atmosphere for $16 \mathrm{~h}$

\begin{tabular}{lll}
\hline Sample & $\begin{array}{l}\text { Temperature } \\
\left({ }^{\circ} \mathrm{C}\right)\end{array}$ & $\begin{array}{l}\text { MCR } \\
(\text { wt \%) }\end{array}$ \\
\hline Raw asphaltenes & - & $40.7 \pm 0.7$ \\
Products from heating asphaltenes & 45 & - \\
$\quad$ in air atmosphere & 55 & $40.6 \pm 0.3$ \\
& 86 & $41.5 \pm 0.6$ \\
& 100 & $41.6 \pm 0.3$ \\
Products from heating asphaltenes & 45 & $40.3 \pm 0.1$ \\
$\quad$ in nitrogen atmosphere & 55 & $40.4 \pm 0.2$ \\
& 86 & $40.6 \pm 0.3$ \\
& 100 & $40.9 \pm 0.2$ \\
\hline
\end{tabular}

The relative changes in absorption at different wave numbers were recorded for relative comparison (Table 5).

In the second set of experiments that were performed at $100{ }^{\circ} \mathrm{C}$, the asphaltenes feed was oxidized with watersaturated air and dry air (Table 4). The infrared spectra of these oxidized products were measured; absorption bands indicating the presence of $\mathrm{C}=\mathrm{O}$ and $\mathrm{C}-\mathrm{O}$ groups confirmed the incorporation of oxygen into the reaction products. Some diversity in the chemical environment of these interactions was observed.

The difference between asphaltenes formation due to oxidation using moist air and dry air can be clearly seen from Fig. 5. There is little difference in the asphaltene content of the raw material and the samples oxidized at $52{ }^{\circ} \mathrm{C}$. However, it seems that at this particular temperature the presence of water during reaction slightly increases the asphaltene content of the products, going from $66.9 \pm 0.6-70.0 \pm 2.1 \mathrm{wt} \%$. On the contrary, the asphaltene content of the products obtained by autoxidation at $100{ }^{\circ} \mathrm{C}$ is significantly higher than the one observed for the products obtained when water was added to the feed at the same temperature $(79.8 \pm 1.6$ and $65.9 \pm 2.2 \mathrm{wt} \%$, respectively). Moreover, when water assisted the oxidation of asphaltenes at $100{ }^{\circ} \mathrm{C}$ no increase in the asphaltene content of the product compared to the raw material was observed.

\section{Discussion}

\section{Benefits from oxidation}

The premise that was investigated by this work is that the yield of maltenes ( $n$-pentane soluble material) can be increased by mild oxidation of asphaltenes, and that these materials may have potential application as petrochemicals $[6,17]$. This claim could not be substantiated by the present experimental investigation, although the beneficial effect of using moist air, rather than dry air was demonstrated.

Under all oxidation conditions there was either no statistically significant change in asphaltenes content, or there was a meaningful increase in asphaltenes content in the oxidized product (Fig. 1; Table 4). Little oxidative degradation took place and oxygen was incorporated in $\mathrm{C}=\mathrm{O}$ and C-O functional groups (Figs. 2, 3, 4). Oxidation may also give rise to addition reactions [19], particularly in materials that are rich in naphtheno-aromatics, such as the asphaltenes feed. Thus, the polarity, solubility parameter and molecular mass of the molecules were likely increased by oxidation. Collectively these changes should result in an increase in asphaltenes content [23], as was indeed observed.

When oxidation was conducted with moist air, the formation of asphaltenes was affected (Table 4); this was particularly evident for oxidation conducted at $100{ }^{\circ} \mathrm{C}$. Oxidation was not prevented, but it was affected by the presence of water. It is not clear in what way the water was able to moderate the oxidation, beyond its obvious dilution effect. Water was present only as a saturated vapor so that dilution was limited. The extent of oxidation moderation by water suggests either some phase equilibrium effect (e.g., gas solubility), or chemical equilibrium effect (e.g.,

Table 4 Asphaltene and micro carbon residue data for unreacted asphaltenes and asphaltenes heated at low temperature in air and moist air atmospheres for different reaction times

\begin{tabular}{|c|c|c|c|c|}
\hline Sample & Temperature $\left({ }^{\circ} \mathrm{C}\right)$ & Time (h) & $\begin{array}{l}\text { Asphaltene } \\
\text { Content (wt } \%)\end{array}$ & $\operatorname{MCR}(w t \%)$ \\
\hline Raw asphaltenes & - & - & $66.9 \pm 0.6$ & $40.7 \pm 0.7$ \\
\hline \multirow[t]{4}{*}{ Products from heating asphaltenes in moist air atmosphere } & 52 & 2 & $70.0 \pm 2.1$ & $40.4 \pm 0.2$ \\
\hline & 52 & 4 & $70.0 \pm 0.1$ & $40.7 \pm 0.2$ \\
\hline & 52 & 8 & $70.5 \pm 1.1$ & $40.2 \pm 0.4$ \\
\hline & 100 & 2 & $65.9 \pm 2.2$ & a \\
\hline \multirow[t]{2}{*}{ Products from heating asphaltenes in air atmosphere } & 52 & 2 & $61.5 \pm 4.7$ & $40.2 \pm 0.6$ \\
\hline & 100 & 2 & $79.8 \pm 1.6$ & $40.3 \pm 0.3$ \\
\hline
\end{tabular}

a The MCR value for this sample was not measured 
Fig. 4 Infrared spectra of raw asphaltenes and total oxidized product after wet air oxidation at $52{ }^{\circ} \mathrm{C}$ for 2,4 and $8 \mathrm{~h}$, respectively

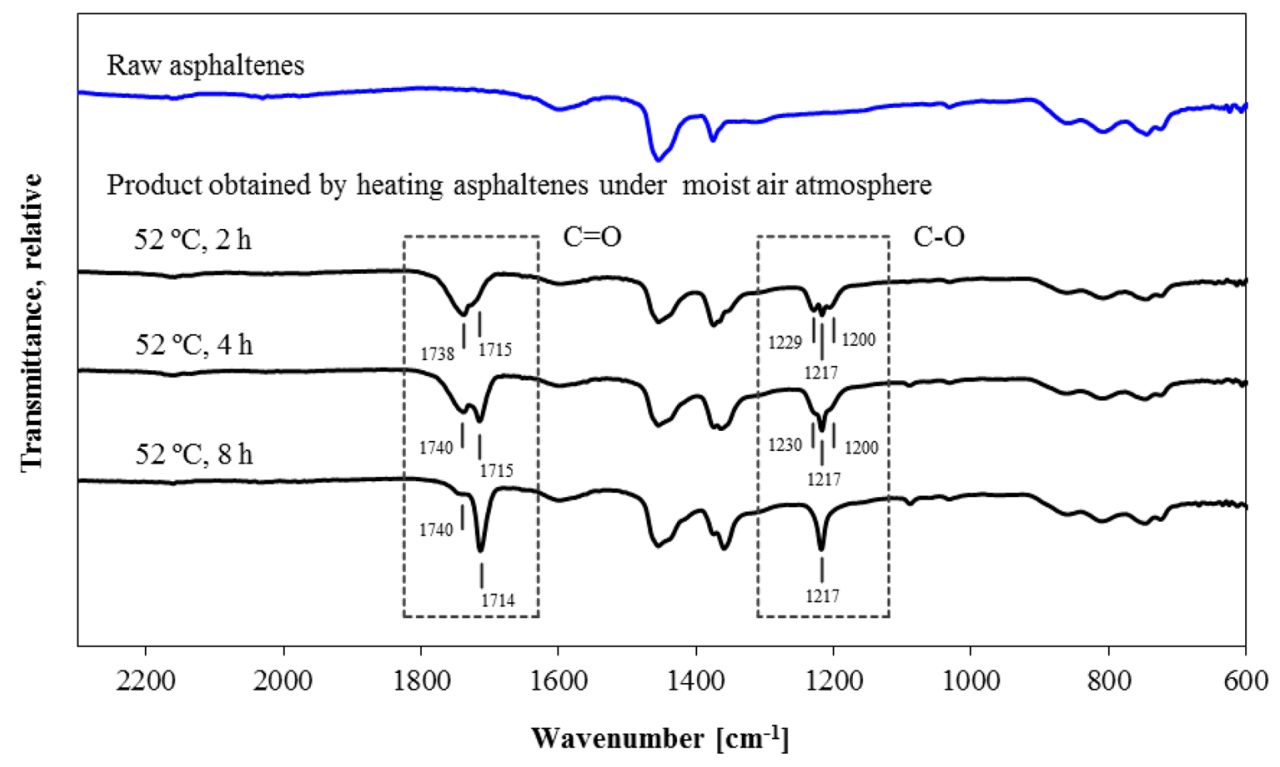

Table 5 Relative peak intensities of absorptions at different regions of the IR spectra for the total oxidized products after oxidation using moist air at $52{ }^{\circ} \mathrm{C}$

\begin{tabular}{|c|c|c|c|c|}
\hline \multirow[t]{2}{*}{ Stretching vibrations $\left(\mathrm{cm}^{-1}\right)$} & \multirow[t]{2}{*}{ Functional group } & \multicolumn{3}{|c|}{ Oxidized asphaltenes } \\
\hline & & $2 \mathrm{~h}$ & $4 \mathrm{~h}$ & $8 \mathrm{~h}$ \\
\hline $1738-1740$ & $\mathrm{C}=\mathrm{O}$ & 3.9 & 3.5 & 1.0 \\
\hline $1714-1715$ & $\mathrm{C}=\mathrm{O}$ & 0.3 & 0.7 & 1.0 \\
\hline 1454 & $\mathrm{C}-\mathrm{H}$ & 0.8 & 0.8 & 1.0 \\
\hline $1229-1230$ & $\mathrm{C}-\mathrm{O}$ & $0.5^{\mathrm{a}}$ & $0.5^{\mathrm{a}}$ & - \\
\hline 1217 & $\mathrm{C}-\mathrm{O}$ & 0.6 & 0.8 & 1.0 \\
\hline 1200 & $\mathrm{C}-\mathrm{O}$ & $0.4^{\mathrm{a}}$ & $0.4^{\mathrm{a}}$ & - \\
\hline
\end{tabular}

a Relative to the absorption at $1217 \mathrm{~cm}^{-1}$ after $8 \mathrm{~h}$ oxidation

hydrolysis-dehydration reaction equilibrium). It was reported that during oxidation of heavy oil at $200{ }^{\circ} \mathrm{C}$ water enhanced $\mathrm{CO}_{2}$ production and that water mitigated some of the other deleterious effects of low-temperature oxidation, such as increased viscosity and acidity [13].

Interestingly, the increase in asphaltenes content was not accompanied by an increase in MCR (Tables 3, 4). The average numeric values suggested a minor increase, but this was not statistically significant. It is usual to correlate these two properties when describing the chemical changes involved in the thermal conversion of oil and oil-derived materials. However, one should understand they measure different characteristics. The asphaltenes content indicates the amount of components soluble in aromatic solvents and insoluble in paraffinic solvents; whereas, the MCR indicates the coke forming tendency of a material. Even molecules with limited solubility and low $\mathrm{H}: \mathrm{C}$ ratio, such as asphaltenes, may go through chemical changes without completely becoming a different solubility class, such as

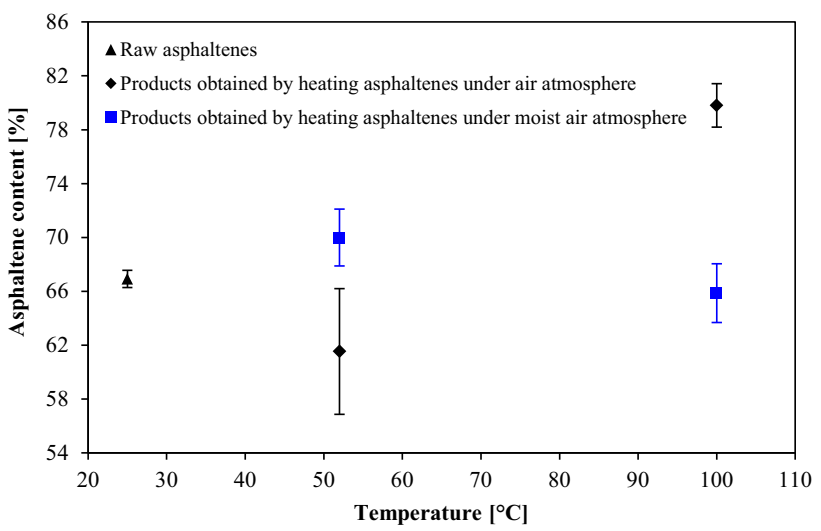

Fig. 5 Asphaltene content of the products obtained by heating asphaltenes for $2 \mathrm{~h}$ at 52 and $100{ }^{\circ} \mathrm{C}$, under air and moist air atmosphere

coke. The solvent-resid phase diagram presented by Wiehe [25] shows that one possible path during conversion of asphaltenes involves changes in their hydrogen content or 
molecular weight without affecting their nature as asphaltenes. Configuration of the molecules changes but they still belong to the same solubility class. On the other hand, it is worth to mention that thermal conversion of asphaltenes may produce more volatile products. Under more severe or prolonged oxidation an increase in MCR is anticipated due to loss of hydrogen as water.

The present work indicated that oxidation of asphaltenes on its own is not enough as upgrading strategy. Oxidation can be considered as a first step in an asphaltene liquefaction scheme, but not the only step. Under the right conditions, when oxygen is inserted into the asphaltenes structure, $\mathrm{C}-\mathrm{C}$ bonds can be broken [15]. However, this type of chemistry was not prevalent under the conditions investigated based on the patent literature [6, 17].

\section{Oxidation selectivity}

The manipulation of oxidation selectivity in complex hydrocarbon mixtures has broader relevance that extends beyond the use of oxidation for asphaltenes upgrading. Oxidation is extensively employed in the petrochemical industry (e.g., [3]). Evaluating the experimental results from this perspective was, therefore, of potential interest.

The selective autoxidation of alkanes is a highly desirable petrochemical conversion, because air oxidation is one of the least costly methods of alkane $\mathrm{C}-\mathrm{H}$ bond activation. The selectivity of free radical hydrocarbon oxidation is mainly influenced by temperature and oxygen availability [4]. Oxygen availability was not changed, except by secondary effects related to changes in the temperature. The nature of the oxygenates formed during asphaltenes oxidation at different temperatures (Fig. 2, 3, 4) changed. Although conversion was also affected, conversion was low in all instances and these changes in the nature of the oxygen-containing functional groups must have been caused mainly by changes in the temperature.

At the lowest temperatures a strong $\mathrm{C}=\mathrm{O}$ band appears near $1715 \mathrm{~cm}^{-1}$ (Table 2). In tandem a $\mathrm{C}-\mathrm{O}$ band appears near $1217 \mathrm{~cm}^{-1}$. If these two absorption bands were related, it would suggest the formation of esters, which would be peculiar, because alcohols and ketones were anticipated to be the primary oxidation products. The strong $\mathrm{C}-\mathrm{O}$ absorption near $1217 \mathrm{~cm}^{-1}$ is more likely that of aromatic ethers, because there is a concomitant increase in absorption in the $1050-1010 \mathrm{~cm}^{-1}$ region (Silverstein 2005), which is particularly apparent as the broad band in the spectra of the oxidized maltenes fraction (Fig. 3). The wave number of the $\mathrm{C}=\mathrm{O}$ absorption is also indicative of an aliphatic ketone, rather than an ester. At the lowest temperatures studied, $\sim 50{ }^{\circ} \mathrm{C}$, the main oxygenate functional group identified by infrared spectroscopy are ketones and aromatic ethers.
As the temperature was increased from $\sim 50$ to $\sim 100{ }^{\circ} \mathrm{C}$, a $\mathrm{C}=\mathrm{O}$ band appeared near $1735 \mathrm{~cm}^{-1}$ and it grew in size relative to the $\mathrm{C}=\mathrm{O}$ band near $1715 \mathrm{~cm}^{-1}$. Simultaneously two $\mathrm{C}-\mathrm{O}$ bands appeared near 1230 and near $1200 \mathrm{~cm}^{-1}$, respectively. If these two absorption bands were related, as they appeared to be (Table 2), then it might be due to the formation of an ester functionality. The wave numbers of the $\mathrm{C}=\mathrm{O}$ and $\mathrm{C}-\mathrm{O}$ absorptions correspond to that reported for esters and cyclic esters (Silverstein 2005). With prolonged wet oxidation these absorption bands decrease over time (Fig. 4; Table 5), which suggested ester hydrolysis and possible carboxylic acid decomposition to eliminate $\mathrm{CO}_{2}$. If this is indeed a correct interpretation, then one should be able to suggest a pathway that would lead to ester formation, despite the mild oxidation conditions and that would explain the temperature sensitivity of this reaction.

A plausible pathway for ester formation that would explain the temperature sensitivity of this reaction can be suggested for the oxidation of cycloalkanes. Since oilsandderived material is rich in multicyclic molecules where cycloalkane and aromatic rings are adjoining [21], indan is a realistic representation of a substructure that will be found in more complex molecules found in asphaltenes. The suggested pathway of ester formation is, therefore, illustrated by the oxidation of indan hydroperoxide as model molecule (Fig. 6). The initial steps leading to the formation of the hydroperoxide are not shown.

Decomposition of the hydroperoxide leads to the formation of the oxygen-centered alkoxy radical of indan (1). The alkoxy radical (1) can abstract hydrogen from another hydrocarbon to produce an alcohol (2). At low temperature this is the dominant pathway. The alkoxy radical (1) can also undergo $\beta$-scission, which leads to ring-opening to produce (3). The $\beta$-scission of (1) requires higher activation energy, but it is nevertheless a well-known and deleterious side reaction during the low-temperature autoxidation of cyclohexane [22]. The carbon-centered radical in (3) is a typical free radical propagation intermediate and will readily be oxidized to form a hydroperoxide intermediate (4). The sequence of steps leading from (3) to (4) is the same as the one involved in the formation of the indan hydroperoxide by the autoxidation of indan. Decomposition of the hydroperoxide (4) takes place in an analogous way to the decomposition of the indan hydroperoxide. However, the fragments of the ring-opened cycloalkane are attached to a structurally ridged unit, the aromatic ring, thereby increasing the probability of an "in cage" reaction. The "in cage" elimination of water and ring closure to form an ester (5) is, therefore, a likely reaction. The ester formation pathway is favored by temperature, because $\beta$-scission leading from (1) to (3) is in competition with hydrogen abstraction (2) and it requires higher activation energy. 
Fig. 6 Reaction pathway explaining ester formation during low-temperature autoxidation of cycloalkanecontaining feed materials, as illustrated by the oxidation of indan

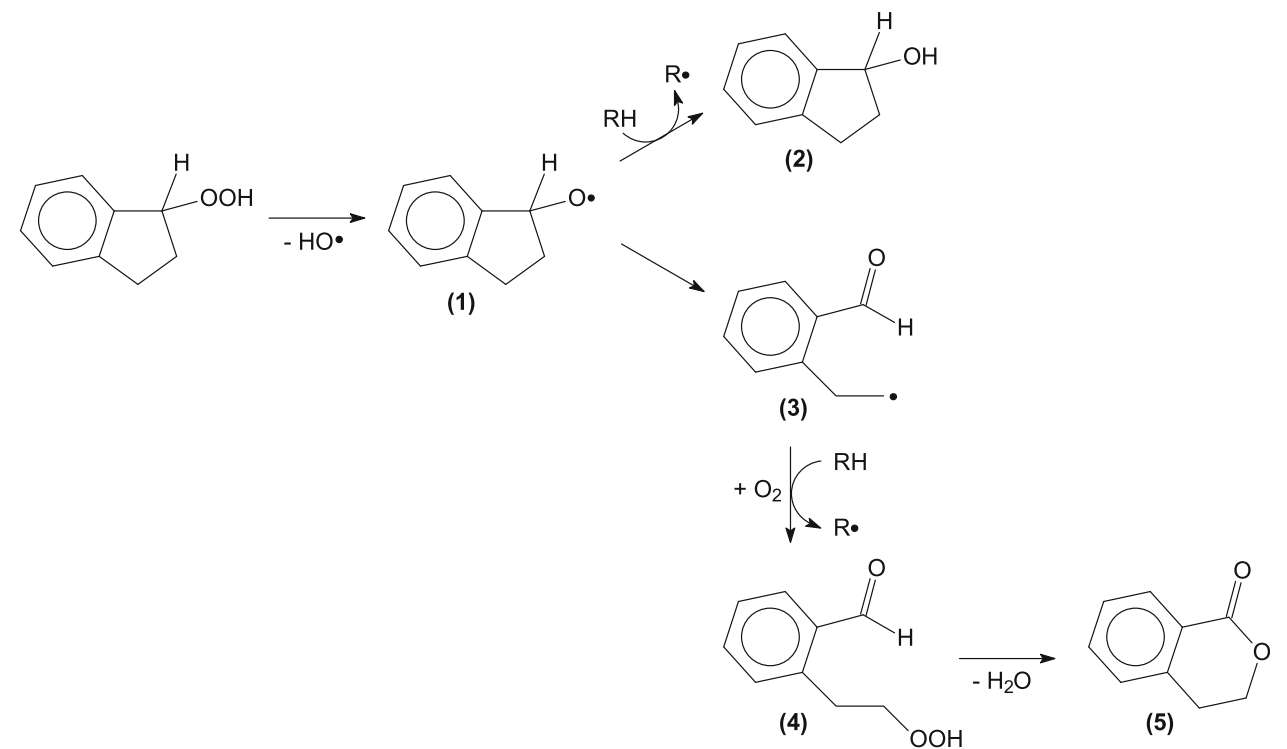

\section{Heating effects on asphaltenes content}

An interesting observation, which was not related to the primary purpose of the investigation, was that the raw asphaltenes feed was detrimentally affected by heating to $100{ }^{\circ} \mathrm{C}$. The asphaltenes content of the feed that was maintained at $100{ }^{\circ} \mathrm{C}$ for $16 \mathrm{~h}$ (Fig. 1) increased compared to the raw material feed, but this was not reflected by a change in MCR value (Table 3). The observed increase in the asphaltenes content on heating under inert atmosphere adds evidence that indicates that oilsands bitumen-derived materials are heat sensitive [9]. Although the exact temperature range for this heat sensitivity has not been determined, prolonged exposure to temperatures in the range $100-150{ }^{\circ} \mathrm{C}$ and possibly somewhat higher temperature, should be avoided.

Oilsand-derived asphaltenes have a high free radical content, of the order $10^{18} \mathrm{spins} / \mathrm{g}$, as measured by electron spin resonance spectroscopy [16]. These free radicals might participate in reactions occurring during heating. It is speculated that due to the restricted mobility of molecules in the asphaltenes, which is a solid at ambient conditions, free radical addition reactions are slow and limited in extent over prolonged periods. However, the molecules and free radicals have the potential to become mobile. It is anticipated that prolonged heating can affect the mobility of these molecules and enable the movement that otherwise would not be possible or would be very slow at lower temperatures. On heating, the increase in the asphaltenes content might reflect molecular rearrangements, self-reactions among the molecules and even inter-molecular free radical addition reactions that took place.

\section{Conclusions}

The possibility of using low-temperature oxidative asphaltenes liquefaction as upgrading strategy to increase the yield of the maltenes fraction was investigated. Dry air and water-saturated air were used as the oxidizing agents. The main conclusions derived from the experimental investigation were:

(a) Little oxidative degradation was observed under all experimental conditions. The presence of $\mathrm{C}=\mathrm{O}$ and $\mathrm{C}-\mathrm{O}$ functional groups confirmed the incorporation of oxygen in the asphaltenes structure.

(b) The impact of the low-temperature autoxidation (oxidation with dry air) on the product properties was evident when the reaction was carried out at relatively high temperatures, particularly $100{ }^{\circ} \mathrm{C}$. A significant increase in the asphaltenes content of the oxidized product was observed.

(c) Although statistically it could not be proven, the experimental data suggests that water was capable of moderating the oxidation by preventing formation of additional asphaltenes. However, beyond the limited dilution effect of water, the influence of water during oxidation is not clear; it might be related either to some phase equilibrium effect (e.g., gas solubility), or chemical equilibrium effect (e.g., hydrolysis-dehydration reaction).

(d) Despite the mild oxidation conditions, changes in the nature of the oxygen-containing functional groups indicated changes in the oxidation selectivity with temperature and due to the increased presence of water in the water-saturated air. 
(e) Spectroscopic evidence was presented that esters were formed during oxidation at $\sim 100{ }^{\circ} \mathrm{C}$ with dry air. The esters formed during oxidation with watersaturated air were not persistent and the esters were converted over time, presumably with hydrolysis as an intermediate reaction step and possible carboxylic acid decomposition to eliminate $\mathrm{CO}_{2}$.

(f) A reaction pathway to explain temperature-dependent ester formation in cycloalkanes was presented. Ester selectivity was determined by the competition between $\beta$-scission and hydrogen abstraction reactions of the alkoxy radical.

(g) Heating of the raw asphaltenes feed under inert (nitrogen) atmosphere has a detrimental effect on its own. The observed increase in the asphaltenes content highlighted the heat sensitivity of the oilsands bitumen-derived materials.

(h) Based on the experimental evidence from the present study, the premise of using low-temperature oxidative asphaltenes liquefaction as upgrading strategy for petrochemical production does not hold. An increase in the yield of the maltene fraction due to mild oxidation of asphaltenes was not observed.

Acknowledgments The contributions of Dominic Lung Ming Lim and Jui Hua Tan are gratefully acknowledged. This work forms part of an investigation of the conversion of asphaltenes and coal that is funded by the Canadian Centre for Clean Coal/Carbon and Mineral Processing Technology $\left(\mathrm{C}^{5} \mathrm{MPT}\right)$.

Open Access This article is distributed under the terms of the Creative Commons Attribution 4.0 International License (http:// creativecommons.org/licenses/by/4.0/), which permits unrestricted use, distribution, and reproduction in any medium, provided you give appropriate credit to the original author(s) and the source, provide a link to the Creative Commons license, and indicate if changes were made.

\section{References}

1. Ancheyta J, Trejo F, Singh Rana M (2009) Asphaltenes: chemical transformation during hydroprocessing of heavy oils. CRC Press, Boca Raton

2. Babu DR, Cormack DE (1984) Effect of oxidation on the viscosity of Athabasca bitumen. Can J Chem Eng 62:562-564

3. Clerici MG, Kholdeeva OA (eds) (2013) Liquid phase oxidation via heterogeneous catalysis. Organic synthesis and industrial applications. Wiley, Hoboken
4. De Klerk A (2003) Continuous-mode thermal oxidation of Fischer-Tropsch waxes. Ind Eng Chem Res 42:6545-6548

5. De Klerk A, Gray M, Zerpa N (2014) Unconventional Oil and Gas: Oilsands. In: Letcher T (ed) Future energy, 2nd edn. Elsevier, Amsterdam, pp 95-115

6. Duyvesteyn WPC, Morley RL (2010) (Marathon Oil Canada Corporation, Calgary, AB). Oxidation of asphaltenes. US Patent 7,811,444 B2, October 12, (2010)

7. Falbe J (ed) (1982) Chemical feedstocks from coal. Wiley, New York

8. García Zapata JL, De Klerk A (2014) Viscosity changes during mild oxidation of oilsands derived bitumen: solvent effects and selectivity. Energy Fuels 28:6242-6248

9. Gonzalez V, De Klerk A (2015) Influence of acid chemistry on bitumen viscosity. Prepr. Pap.-Am. Chem. Soc. Div. Energy Fuels 60(1):9-12

10. Grey MR (2015) Upgrading oilsands bitumen and heavy oil. University of Alberta Press, Edmonton

11. Herrington PR (1998) Oxidation of bitumen in the presence of a constant concentration of oxygen. Petrol Sci Technol 16:1061-1084

12. Hudlický M (1990) Oxidations in organic chemistry (ACS Monograph Ser. 186). American Chemical Society, Washington

13. Lee DG, Noureldin NA (1989) Effect of water on the low-temperature oxidation of heavy oil. Energy Fuels 3:713-715

14. Leprince P (ed) (2001) Petroleum refining: Vol 3 conversion processes. Paris, EditionsTechnip, pp 381-407

15. Sanchez NM, De Klerk A (2014) Oxidative ring-opening over metal oxides. Prepr. Pap.-Am. Chem. Soc. Div. Energy Fuels 59(2):558

16. Niizuma S, Steele CT, Gunning HE, Strausz OP (1977) Electron spin resonance study of the free radicals in Athabasca asphaltene. Fuel 56:249-256

17. Pitchford AC (1969) (Phillips Petroleum Company, Delaware). Asphaltene oxidation. US Patent 3,484,365, December 16, (1969)

18. Siddiquee MN, De Klerk A (2013) Continuous and prolonged oxidation of bitumen for upgrading by microbial digestion. Prepr. Pap.-Am. Chem. Soc., Div. Energy Fuels 58(2):649-651

19. Siddiquee MN, De Klerk A (2014) Hydrocarbon addition reactions during low-temperature autoxidation of oilsands bitumen. Energy Fuels 28:6848-6859

20. Silverstein RM, Webster FX, Kiemle DJ (2005) Spectroscopic identification of organic compounds, 7th edn. Wiley, New York

21. Strausz OP, Lown EM (2003) The chemistry of Alberta oil sands, bitumens and heavy oils. Alberta Energy Research Institute, Calgary

22. Tolman CA, Druliner JD, Nappa MJ, Herron N (1989) Alkane oxidation studies in Du Pont's central research department. In: Hill CL (ed) Activation and functionalization of alkanes. Wiley, New York, pp 303-360

23. Wiehe IA (2008) Process chemistry of petroleum macromolecules. CRC Press, Boca Raton

24. Wiehe IA (1993) A phase-separation kinetic model for coke formation. Ind Eng Chem Res 32:2447-2454

25. Wiehe IA (1992) A solvent-resid phase diagram for tracking resid conversion. Ind Eng Chem Res 31:530-536 